\title{
A Prospective Comparative Evaluation of Extra Cranial Vessels by Contrast Enhanced Magnetic Resonance Angiography Versus Colour Doppler in Patient with Stroke
}

\author{
Pasam Kusumalatha ${ }^{1}$ \\ ${ }^{1}$ Assistant Professor, Department of Radiology, Rangaraya Medical College, Kakinada, India
}

Corresponding author: Pasam Kusumalatha, Assistant Professor, Department of Radiology, Rangaraya Medical College, Kakinada, India

DOI: http://dx.doi.org/10.21276/ijcmsr.2019.4.3.22

How to cite this article: Pasam Kusumalatha. A prospective comparative evaluation of extra cranial vessels by contrast enhanced magnetic resonance angiography versus colour doppler in patient with stroke. International Journal of Contemporary Medicine Surgery and Radiology. 2019;4(3):C97-C101.

\section{A B S T R A C T}

Introduction: Management of stroke depends upon accuracy and promptness of the diagnosis. Further management often acute episodes also depends upon the accuracy of the, diagnosis. Various modalities of evaluations are available for detecting pathology in extracranial blood vessels. Present study was designed to evaluate the diagnostic value of contrast enhanced magnetic resonance angiography in comparison with Doppler for diagnosis of pathologies in extra cranial blood vessels in patients with stroke.

Material and method: Based on exclusion and inclusion criteria 60 patients were enrolled for this study. A detailed clinical history of the patients was taken and clinical examination was performed. Magnetic resonance angiography was performed by 1.5 Tesla 16 channel MRI with an ultrafast $120 \mathrm{mt}$ slow rate and high $33 \mathrm{mt} / \mathrm{m}$ peak amplitude whole body gradient. A circularly polarized phased array neck coil was placed. Colour Doppler examination of the blood vessels was done by Esoate my lab class c USG machine, with 6-12 MHz linear array HD probe. The assessment was done for internal carotid, external carotid and both vertebral arteries, peak systolic velocities, end diastolic velocities and Doppler spectral analysis was used for estimation of carotid artery stenosis.

Result: The pathology detected by contrast enhanced magnetic angiography was $10(16.6 \%)$ in bulb, but pathology detected by colour Doppler was9(15\%) out of 60 patients 38(63.3\%) patient were detected pathology in vertebral artery by CE MRA and $40(66.6 \%)$ patients were detected pathology in vertebral artery by colour Doppler. Location of stenosis was detected in ICA in 4 patients by both modalities. Two patients were detected thrombosis in CCA by both modalities, 34 patients have thrombosis detected by Doppler and 32 patients have thrombosis detected by CE MRA in internal carotid artery. 36 patients in VA were detected thrombosis by colour Doppler, but thrombosis detected by CE MRA in VA was in 34 patients.

Conclusion: CE MRA has better discriminatory power compared to colour Doppler in detecting $80-99 \%$ stenosis. Colour Doppler was better role in the evaluation of morphology of plaque most common site of athromatous plaque was carotid bulb which was equally detected by both modalities.

Keyword: Contrast Enhanced Magnetic Resonance Angiography, Colour Doppler, Extra Cranial Vessels

\section{INTRODUCTION}

Non communicable diseases are responsible for $71 \%$ of all deaths globally, that is 41 million people each year. Each year $85 \%$ of the premature death occurs due to non communicable disease in low and middle income courtiers. ${ }^{1}$ Management of non-communicable disease includes detecting, screening and treatment, but early detection and timely intervention can reduce the need for expansive treatment. ${ }^{2}$ Among noncommunicable disease, cerebrovascular accidents (stoke) are the second leading cause of death and third leading cause of disabilities. $^{3}$

A stoke is caused by the interruption of the blood supply to brain either because of rapture of cranial blood vessels or blocked of the blood vessels by the clot. Management of stroke depends upon accuracy and promptness of the diagnosis. Further management often acute episodes also depends upon the accuracy of the, diagnosis, It has been reported by chaturvedi et al,that carotid endaterectomy has been proved beneficial for patient with $50 \%$ to $99 \%$ block. $^{4}$ It carotid artery stenos is detected early ever $60 \%$ to $99 \%$ stenosis patient would be operated with very low risk.

Various modalities of evaluations are available for detecting pathology in extracranial blood vessels. Present study has be designed to evaluable the diagnostic value of contrast enhanced magnetic resonance angiography in comparison with Doppler for diagnosis of pathologies in extra cranial blood vessels in patients with stroke.

Digital subtraction angiography is considered to be gold standard for the diagnosis of the pathology of coronary 
artery, but as it is a invasive procedure and the rate of stroke because of this procedure ranges from 0.5 to $1 \%$, there for non invasive procedure like contrast enhanced MRI and Doppler ultrasound is current focus of research. ${ }^{6,7}$

Doppler ultrasound is non invasive, safe and less expansive modality for visualisation of extra cranial vessels; it is operator dependent and limited to cervical portion of blood vessels. Contrast enhanced MRA using gadolinium is highly sensitive and specific modality which can produce a reproducible three dimensional image of the extra cranial blood vessels. More distal blood vessels can also be assessed and it is not depend upon operator. ${ }^{8,9}$ Present study was designed to evaluate the diagnostic value of contrast enhanced magnetic resonance angiography in comparison with Doppler for diagnosis of pathologies in extra cranial blood vessels in patients with stroke.

\section{MATERIAL AND METHODS}

This was a prospective comparative study conducted in the deportment of Radio diagnosis Rangaraya medical college and GGH Kakinada Andhra Pradesh from Jan 2016 to March 2019. Based on the result of previous studies and assuming power of $80 \%$ and $\alpha$ - error 0.05 the sample size for this study was calculated to be 60 . For the calculation of sample size we used CLICALC.com, sample size calculator. This study was approved by the institutional ethics committee. A written informed consent was taken from all the patients and his attendants.

\section{Selection of subject}

Patients in this study were enrolled as per inclusion and exclusion criteria.

\begin{tabular}{|l|l|}
\hline Inclusion criteria & Exclusion criteria \\
\hline Age above 30yrs, Both sex & $\begin{array}{l}\text { Hypersensitivity to contrast } \\
\text { given }\end{array}$ \\
$\begin{array}{l}\text { Nts with sign and symptoms } \\
\text { of stroke or TIA }\end{array}$ & given consent \\
\hline
\end{tabular}

\section{Method}

Based on exclusion and inclusion criteria 60 patients were enrolled for this study. A detailed clinical history of the patients were taken and clinical examination was preformed All MR examination was performed by GE 1.5 Tesla signa HDXT 16 channel, MRI. Patients were prepared for MRI scan as per the protocol and were explained about the procedure to him. Histories of allergies to drugs were taken. Patients were also evaluated for any medical devices used for therapeutic purpose like cochlear implant, pacemaker, stent, aneurysm clip and compatibility of those devices for MRI.

Patient was placed inside the opening of the MRI, two to six imaging sequences each taking two to 15 min were taken Each sequence provides specific image orientation and decrees of clarity. Gadolinium was used as contrast material and was injected during one of the specific sequence.

Magnetic resonance angiography was performed by 1.5 Tesla 16 channel MRI with an ultrafast $120 \mathrm{mt}$ slow rate and high $33 \mathrm{mt} / \mathrm{m}$ peak amplitude whole body gradient. A circularly polarized phased array neck coil was placed. 3D TOF MR Angiography and 3D gadolinium- CE MRA was performed after obtaining classic fast spoiled gradient echo axial, sagittal and coronal localisers. Each of seven slabs of multislab 3D time of flight technique comprised with 32 axial section, thickness $1.41 \mathrm{~mm}$ bond with superior saturation, and $39 / 7$ (TR/TE), flip angle 250, 160x 256 matrix size, and 250x 250x $90 \mathrm{~mm}$ field of view image quality. 3D gadolinium $\mathrm{CE}$ MRA was per formed $15 \mathrm{ml}$ of contrast media was injected in anti cuboital vein at the rate of 2 to $3 \mathrm{ml} / \mathrm{sec}$ at the start of the scan, followed by $15 \mathrm{ml}$ saline. Five consecutive $3 \mathrm{D}$ sequences are performed. Turbo MRA performed with a $1.5 \mathrm{~m} \mathrm{sec} \mathrm{TR,}$ $30^{\circ}$ flap angle, 300x225 mm field view, 320x100 matrix and 42 partitions each $2 \mathrm{~mm}$ thick with zero filling in the $\mathrm{Z}$ - axis, which has given images in 4see. CE MRA was reviewed after processing with maximum intensity projector.

Colour Doppler examination of the blood vessels was done by Esoate my lab class c USG machine, with 6-12 $\mathrm{MHz}$ linear array $\mathrm{HD}$ probe. The assessment was done for internal carotid, external carotid and both vertebral arteries, peak systolic velocities. End diatolic velocities and Doppler spectral analysis was used for estimation of carotid artery stenosis (figure 1,2). ${ }^{10}$ For grading of stenos is NASCET criteria was used. ${ }^{11}$

\section{STATISTICAL ANALYSIS}

For the analysis of data we used SPSS 16.0 version of software for the parametric date, we used paired proportion test for two proportion and $\mathrm{P}$ value less than 0.05 were taken significant.

\section{RESULT}

As per inclusion and exclusion criteria 60 patients were included in this study out of 60 patients one patient were below 40 yrs of age, $8(13.3 \%)$ patients were between 41 to 50 yrs of age. 14 patients were between 51 to 60 yrs of age. Most of the patients were between $61 \mathrm{yrs}$ to $70 \mathrm{yrs}$ of age that is $46.6 \% .15 \%$ patients were above $71 \mathrm{yrs}$ of age. There was 10 female and 50 male patients in this group. Regarding clinical presention of the patients, 24 (90\%) patients were presented with stroke, hemiparesis was presentation in 20 (33.33\%) patients. Eight patients were presented with weakness that is $13.33 \%$ and rest eight patient were presented with cerebrovascular accident (table-1).

As per table-2 the pathology detected by contrast enhanced magnetic resonance angiography in internal resonance angiography in internal carotid artery was 36 (60\%) out of 60 patients and pathology detected by colour Doppler in ICA was 38 that is $63.30 \%$ one patient has pathology in external carotid artery detected by CA MRA and colour Doppler both, which is similar to common carotid artery there also since pathology was detected by both modulates.

The pathology detected by contrast enhanced magnetic angiography was $10(16.6 \%)$ in bulb, but pathology detected by colour Doppler was 9 (15\%) out of 60 patients 38 (63.3\%) patient were detected pathology in vertebral artery by $\mathrm{CE}$ MRA and 40 (66.6\%) patients were detected pathology in vertebral artery by colour Doppler.

From table 3, 16-49\% stenosis was detected by CE MRA in internal carotid artery of one patient but not detected by colour Doppler. One patient was detected 10 to $49 \%$ occlusion $\mathrm{n}$ external carotid artery by both modalities. Four 
patients were having 16-49\% occlusion in bulb detected by CE MRA and 2 patients having occlusion in bulb detected by colour Doppler. Vertebral artery has no occlusion between 16-49\%, detected by both modalities. These finding were not significant statistically because $\mathrm{p}$ value was more than 0.05 . 50-69\%, stenosis was absent in common carotid, external carotid and vertebral artery as detected by both modalities. 50 to $69 \%$ occlusion was detected in one patient in internal carotid artery by colour Doppler but was not detected by CE MRA which is not significant statistically ( $p=0.3273$ ).

\begin{tabular}{|l|l|c|c|}
\hline \multicolumn{2}{|l|}{ variables } & Number & Percentage \\
\hline Age & $30-40$ & 1 & $1.6 \%$ \\
\cline { 2 - 4 } & $41-50$ & 8 & $13.3 \%$ \\
\cline { 2 - 4 } & $51-60$ & 14 & $23.3 \%$ \\
\cline { 2 - 4 } & $61-70$ & 28 & $46.6 \%$ \\
\cline { 2 - 4 } & $>71$ & 9 & $15 \%$ \\
\hline \multirow{4}{*}{ Sex } & $\mathrm{M} / \mathrm{F}$ & 10 & $16.6 \%$ \\
\cline { 2 - 4 } & & 50 & $83.4 \%$ \\
\hline \multirow{4}{*}{ Tabinical history } & stroke & 24 & $40 \%$ \\
\cline { 2 - 4 } & TIA & 20 & $33.33 \%$ \\
\cline { 2 - 4 } & weakness & 8 & $13.33 \%$ \\
\cline { 2 - 4 } & CVA & 8 & $13.33 \%$ \\
\hline \multicolumn{3}{|c|}{ Tabemography of the patients. } \\
\hline
\end{tabular}

Two patients having stenosis between 50 to $69 \%$ in blub detected by CE MRA but not detected by Doppler which is not significant statistically $(\mathrm{p}=0.1551)$. Stenosis between 70 to $79 \%$ was not detected in CCA, ECA, and VA by both modalities. But it was detected in one patient in ICA and 4 patients in bulb by both modalities. 80to $99 \%$ stenosis was absent in CCA, ECA and VA. Two patients having 80 to $99 \%$ stenosis in ICA detected by CE MRA and 6 patients having stenosis $80 \%-99 \%$ detected by CE MRA in bulb, both were not detected by Doppler second finding was significant statistically. Complete occlusion was absent in ECA and bulb. Complete occlusion was present in one patient in CCA detected by both modalities, complete occlusion was detected in 32 patients in ICA detected by CE MRA but 34 patients in ICA were detected complete occlusion by colour Doppler. 34 patients in VA have complete occlusion detected by $\mathrm{CE}$ MRA and 36 patients have complete occlusion detected by colour Doppler. Location of stenosis was detected in ICA in 4 patients by both modalities. Two patients were detected thrombosis in CCA by both modalities, 34 patients have thrombosis detected by Doppler and 32 patients have thrombosis detected by CE MRA in internal carotid artery. 36 patients in VA were detected thrombosis by colour Doppler, but thrombosis detected by CE MRA in VA was in 34 patients.

\begin{tabular}{|c|c|c|c|c|c|c|c|c|c|c|}
\hline \multirow[t]{3}{*}{ Modalities } & \multicolumn{10}{|c|}{ Extra cranial vessels ( $n=60$ ) (number of pathology) } \\
\hline & \multicolumn{2}{|c|}{ ICA } & \multicolumn{2}{|c|}{ ECA } & \multicolumn{2}{|c|}{ CCA } & \multicolumn{2}{|c|}{ BULB } & \multicolumn{2}{|c|}{ VA } \\
\hline & $\begin{array}{c}\text { Numbers } \\
\text { (\%) }\end{array}$ & P Value & $\begin{array}{c}\text { Numbers } \\
\text { (\%) }\end{array}$ & P Value & $\begin{array}{c}\text { Numbers } \\
\text { (\%) }\end{array}$ & P Value & $\begin{array}{c}\text { Numbers } \\
\text { (\%) }\end{array}$ & P Value & $\begin{array}{c}\text { Numbers } \\
(\%)\end{array}$ & P Value \\
\hline CE MRA & $36(60 \%)$ & \multirow[t]{2}{*}{0.07} & $1(1.6 \%)$ & \multirow[t]{2}{*}{1} & 1 & \multirow[t]{2}{*}{1} & $10(16.6 \%)$ & \multirow[t]{2}{*}{0.071} & $38(63.4 \%)$ & \multirow[t]{2}{*}{0.07} \\
\hline $\begin{array}{l}\text { Color } \\
\text { doppler }\end{array}$ & $38(63.41 \%)$ & & $1(1.6 \%)$ & & 1 & & 9(15\%) & & $40(66.6 \%)$ & \\
\hline
\end{tabular}

CE MRA= contrasted enhanced magnetic resonance angiography, $C D=$ colour doppler, $c c a=$ common carotid artery,ica=internal carotid artery,eca $=$ external carotid artery, va $=$ vertebral artery.

Table-2: Pathology defected by various modalities in extra cranial vessels

\begin{tabular}{|c|c|c|c|c|c|c|c|c|c|c|c|}
\hline \multirow[t]{2}{*}{ Pathology } & \multirow[t]{2}{*}{ Modality } & \multicolumn{2}{|c|}{ CCA } & \multicolumn{2}{|c|}{ ICA } & \multicolumn{2}{|c|}{ ECA } & \multicolumn{2}{|c|}{ BULB } & \multicolumn{2}{|l|}{ VA } \\
\hline & & $\begin{array}{c}\text { Numbers } \\
(\%)\end{array}$ & $\begin{array}{c}P \\
\text { value }\end{array}$ & $\begin{array}{c}\text { Numbers } \\
(\%)\end{array}$ & $\begin{array}{c}P \\
\text { value }\end{array}$ & $\begin{array}{c}\text { Numbers } \\
(\%)\end{array}$ & $\begin{array}{c}\mathrm{P} \\
\text { value }\end{array}$ & $\begin{array}{c}\text { Numbers } \\
(\%)\end{array}$ & $\begin{array}{c}P \\
\text { value }\end{array}$ & $\begin{array}{c}\text { Numbers } \\
(\%)\end{array}$ & $\begin{array}{c}P \\
\text { value }\end{array}$ \\
\hline \multicolumn{12}{|l|}{ Stenosis } \\
\hline \multirow[t]{2}{*}{$16-49 \%$} & CE MRA & 0 & & $1(1.6 \%)$ & \multirow[t]{2}{*}{0.3273} & $1(1.6 \%)$ & \multirow[t]{2}{*}{1} & $4(6.6 \%)$ & \multirow[t]{2}{*}{0.4049} & 0 & \\
\hline & $C D$ & 0 & & 0 & & $1(1.6 \%)$ & & $2(3.3 \%)$ & & 0 & \\
\hline \multirow[t]{2}{*}{$50-69 \%$} & CE MRA & 0 & & 0 & \multirow[t]{2}{*}{0.3273} & 0 & & $2(3.3 \%)$ & \multirow[t]{2}{*}{0.1551} & 0 & \\
\hline & $C D$ & 0 & & $1(1.6 \%)$ & & 0 & & 0 & & 0 & \\
\hline \multirow[t]{2}{*}{$70-79 \%$} & CE MRA & 0 & & $1(1.6 \%)$ & \multirow[t]{2}{*}{1} & 0 & & $4(6.6 \%)$ & \multirow[t]{2}{*}{1} & 0 & \\
\hline & $C D$ & 0 & & $1(1.6 \%)$ & & 0 & & $4(6.6 \%)$ & & 0 & \\
\hline \multirow[t]{2}{*}{$80-99 \%$} & CE MRA & 0 & & $2(3.3 \%)$ & \multirow[t]{2}{*}{0.1551} & 0 & & $6(10 \%)$ & \multirow[t]{2}{*}{0.012} & 0 & \\
\hline & $C D$ & 0 & & 0 & & 0 & & 0 & & 0 & \\
\hline \multirow{2}{*}{$\begin{array}{l}\text { Complete } \\
\text { occlution }\end{array}$} & CE MRA & $1(1.6 \%)$ & \multirow[t]{2}{*}{1} & $32(53.3 \%)$ & \multirow[t]{2}{*}{0.7456} & 0 & & 0 & & $34(56.6 \%)$ & \multirow[t]{2}{*}{0.7126} \\
\hline & $C D$ & $1(1.6 \%)$ & & $34(56.6 \%)$ & & 00 & & 0 & & $36(60 \%)$ & \\
\hline \multirow[t]{2}{*}{ Location } & CE MRA & 0 & & $4(6.6 \%)$ & \multirow[t]{2}{*}{1} & 0 & & $9(15 \%)$ & \multirow[t]{2}{*}{1} & 0 & \\
\hline & $C D$ & 0 & & $4(6.6 \%)$ & & 0 & & $9(15 \%)$ & & 0 & \\
\hline \multirow[t]{2}{*}{ Thrombin } & CE MRA & $2(3.3 \%)$ & \multirow[t]{2}{*}{1} & $32(53.3 \%)$ & \multirow[t]{2}{*}{0.7456} & 0 & & 0 & & $34(56.6 \%)$ & \multirow[t]{2}{*}{0.7126} \\
\hline & $C D$ & $2(3.3 \%)$ & & $34(56.6 \%)$ & & 0 & & 0 & & $36(60 \%)$ & \\
\hline
\end{tabular}



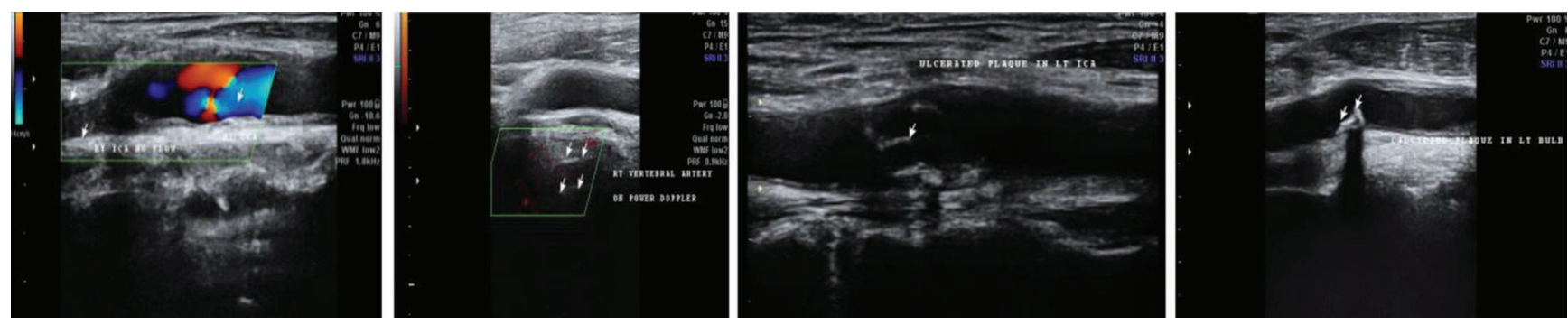

Figure-1:USG image showing complete thrombosis of right proximal ICA with no flow, ulcerated fibro-fatty plaque on color doppler imaging
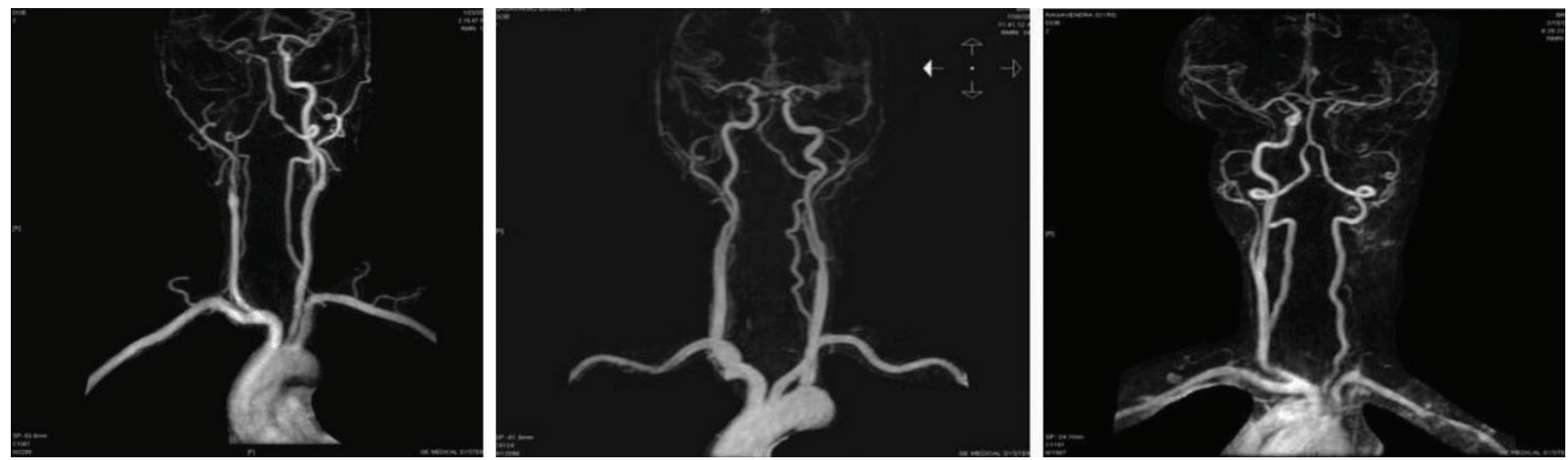

Figure-2: MRA showing complete occlusion of entire right ICA, complete occlusion of right vertebral artery, complete occlusion of left common carotid artery

\section{DISCUSSION}

During last 2 years and two months 60 stroke patients were enrolled for this study to compare the contrast enhanced magnetic resonance angiography with colour Doppler for detecting pathology in extra cranial vessels.

In present study we have observed that most common age group presented with was 61 to $70 \mathrm{yrs},(46.3 \%)$ followed by $51-60 \mathrm{yrs}(23.3 \%)$. There was male predominance $(\mathrm{M} / \mathrm{F}=$ 83.6/16.6\%) This finding corroborates with the finding of Young GR et al. ${ }^{12}$

Regarding clinical history of the patient out of 60 patients $40 \%$ patients were having stroke followed by TIA. This finding is not supported by Young GR et $\mathrm{al}^{12}$ Transient ischemic attack was more common. This finding is supported by the work of cai Jing Jing et al. ${ }^{13}$

In our study the result shows agreement between two modalities when detecting and accessing the pathology in external vessels. In present study CE MRA detected pathology in 60\% ICA and Doppler detected pathology in 63.4\% ICA but was not significant statistically $\mathrm{P}=0.071$ similarly both modality detected equal number of pathology in ECA and CCA. There was significant difference between detection of total pathology in bulb and vertebral artery by both modalities. This finding is supported by the work of Paul j. Nederkoorn et al. ${ }^{14}$ we have found that detection of 16-49\% of stenosis was little more in CE MRA then colour Doppler in ICA, ECA and VA, but was not significant statistically. But there is difference between detection of stenosis in bulb (6.6\% vs 3.3\%) having $\mathrm{P}$ value - 0.411 , which is not significant. This finding is supported by the study of Young GR et $\mathrm{al}^{12}$ and Ricott JJ et al. ${ }^{15}$

In our study comparison of the Doppler and CE MRA finding in evaluation of 50 to $69 \%$ stenosis, CE MRA shows, shows abnormalities in $2(6.67 \%)$ patient in bulb whereas $\mathrm{CD}$ it was 0.similary CD show one abnormality in ICA CE MRA shows 0 . This is supported by the work of $\mathrm{P}$ value $\mathrm{J}$. Nederkoorn et al and comerota $\mathrm{Aj}$ et al. ${ }^{14,16}$ In detection of stenosis between 70 to $89 \%$ both the modalities are comparable to each other.

In comparison of detection of abnormalities by two modalities CE MRA detected two occlusions in ICA and 6 abnormalities in blub but colour Doppler detected 0 . The $P$ value was 0.1551 and 0.0123 respectively, so CE MRA is sensitive for detection of abnormality in bulb than colour Doppler. Both the modalities are comparable to each other in detection of total occlusion, because abnormal finding are equal in both group. $\mathrm{P}$ value more than 0.05 . This finding is supported by the work of Hinal Bhag et al. ${ }^{17}$ In present study we have found that bulb is the common site for plaque that is identified in 9 patients, in four patients is was found at ICA. This finding corroborates with the work of Polak et al. ${ }^{18}$ Regarding comparison of two modalities in the evaluation of thrombosis, abnormality found were equal in both group. This finding corroborates with the finding of lukanova et al. ${ }^{19}$

\section{CONCLUSION}

Contrast enhanced magnetic resonance angiography and colour Doppler permit non-invasive, evaluation of patients with cerebrovascular disease. CE MRA has better discriminatory power compared to colour Doppler in detecting 80-99\% stenosis. Colour Doppler was better role in the evaluation of morphology of plaque most common site of athromatous plaque was carotid bulb which was equally detected by both modalities. 


\section{REFERENCES}

1. Noncommunicable diseases, Fact sheets, World health organisation, 1 June 2018 can be downloaded, https:// www.who.int/en/news-room/fact-sheets/detail/ noncommunicable-diseases

2. GBD 2015 Risk Factors Collaborators. Global, regional, and national comparative risk assessment of 79 behavioural, environmental and occupational, and metabolic risks or clusters of risks, 1990-2015: a systematic analysis for the Global Burden of Disease Study 2015. Lancet 2016; 388(10053):1659-1724.

3. Global Health Estimates. Geneva: World Health Organization; 2012. Available from: http://www.who. int/healthinfo/global_burden_disease/en/.

4. Chaturvedi S., Bruno A., Feasby T., et al. Carotid endarterectomy —an evidence-based review: report of the Therapeutics and Technology Assessment Subcommittee of the American Academy of Neurology. Neurology 2005;65(2):794-801.

5. Executive Committee for the Asymptomatic Carotid Atherosclerosis Study Endarterectomy for asymptomatic carotid artery stenosis. JAMA 1995;273(2):1421-1428.

6. Zhao H, Wang J, Liu X, Zhao X, Hippe DS, Cao Y, Wan J, Yuan C and Xu J. Assessment of carotid artery atherosclerotic disease by using three-dimensional fast black-blood MR imaging: Comparison with DSA. Radiology. 2015;274(2):508-16.

7. Elias RM,WaldJT and Kallmes DF: Diagnosis of carotid artery stenosis with oculopneumoplethysmography alone and in combination with MRA. Vasc Health Risk Manag. 2012;8(5):631-9.

8. Wardlaw JM, Chappell FM, Stevenson M, et al. Accurate, practicaland cost-effective assessment of carotid stenosis in the UK. Health Technol Assess 2006;10(30):iii-iv, ix-x, 1-182.

9. Weber J, Veith P, Jung B, et al. MR angiography at 3 Tesla to assessproximal internal carotid artery stenoses: contrast-enhanced or 3Dtime-of-flight MR angiography? Clin Neuroradiol 2015;25(1):41-48.

10. Gaines PA, Hodgson TJ, Aldoori MI, Beard JD. The investigation of extracranial carotid disease. In: Salmasi A-M, Strano A., Eds, Angiology in Practice. Kluwer Academic Publishers, 1996.

11. North American Symptomatic Carotid Endarterectomy TrialMethods, patient characteristics, and progress. Stroke 1991; 22(1):711-720.

12. Young GR, Humphrey PR, Shaw MD, Nixon TE, Smith ET. Comparison of magnetic resonance angiography, duplex ultrasound, and digital subtraction angiography in assessment of extracranial internal carotid artery stenosis. J Neurol Neurosurg Psychiatry. 1994;57(12):1466-1478.

13. Cai, Jingjing, MD; Wu, Dan, MD; Mo, Yongqian, MD; Wang, Anxin, MD; Hu, Shiyu, MD; Ren, Lijie, MD, Comparison of extracranial artery stenosis and cerebral blood flow, assessed by quantitative magnetic resonance, using digital subtraction angiography as the reference standard. Medicine 2016;95(6):p e5370.

14. Paul J. Nederkoorn, Yolanda van der Graaf and M.G. Myriam Hunink,Duplex Ultrasound and Magnetic Resonance Angiography Compared With Digital
Subtraction Angiography in Carotid Artery Stenosis. Stroke. 2003;34(3):1324-1331

15. Ricotta JJ, Bryan FA, Bond MG et al. Multicentre validation study of real-time (B-Mode) ultrasound, arterio-graphy, and pathological examination. J7VascSurg1987;6(5):512-20.

16. Comerota AJ, Cranley JJ, Katz ML et al. Real-time B-mode carotid imaging. A three-year multicentre experi-ence. JfVascSurg1984;1(5):84-95.

17. Hinal Bhagat, Pratik K Pesivadia, Mahesh Vadel, Purvi D Desai. A study on correlation of colour doppler and MRI in patient of cerebrovascular stroke. Natl J Med Res. 2014; 4(4): 361-365

18. Polak JF, Bajakian RL, O'Leary DH, Anderson MR, Donaldson MC, Jolesz FA. Detection of internal carotid artery stenosis: comparison of MR angiography, color Doppler sonography, and arteriography. Radiology. 1992;182(1):35-40

19. Lukanova DV, Nikolov NK, Genova KZ, Stankev MD, Georgieva EV. The Accuracy of Noninvasive Imaging Techniques in Diagnosis of Carotid Plaque Morphology. Open Access Maced J Med Sci. 2015;3(2):224-230.

\section{Source of Support: Nil; Conflict of Interest: None}

Submitted: 01-06-2019; Accepted: 30-06-2019; Published online: 17-08-2019 